Dossiê: Religião e globalização

\title{
Movimientos cabalistas en el mundo global Entre la tradición y la alta modernidad
}

Kabalist movements in the global world

Between tradition and high modernism

Lelio Nicolás Guigou Mardero*

Resumen: Este artículo trata de los contemporáneos movimientos de creencias cuya piedra angular se basa en la tradición de la Kabbalah, considerando las transformaciones que los mismos han vivido en nuestra alta modernidad. Analizamos estos movimientos como sujetos productores de los actuales procesos de globalización, en la medida que el mundo global e interconectado constituye una de las principales justificativas tanto de sus actuales características como de sus acciones. Desde esta mirada, se indaga el movimiento cabalista Bnei Baruch y su singular recorrido, considerando su relación con la tradición de la Kabbalah y su actual puesta en escena por medio de las narrativas generadas en espacios virtuales y reales.

Palabras claves: Modernidad. Globalización. Kabbalah. Bnei Baruch.

Abstract: This article deals with the contemporary movements of beliefs whose cornerstone is based on the Kabbalah tradition, considering the transformations they have experienced in our high modernity. We analyze these movements as producing subjects of the current processes of globalization, to the extent that the globalized and interconnected world constitutes one of the main justifications both of their current characteristics and their actions. From this viewpoint the Kabbalist movement Bnei Baruch and its singular journey are analized, considering its relationship with the Kabbalah tradition and its actual staging through the narratives generated in virtual and real spaces.

Keywords: Modernity. Globalisation. Kabbalah. Bnei Baruch.

* Doctor en Antropología Social por la Universidade Federal do Rio Grande do Sul (Ufrgs, Porto Alegre, RS, Brasil), artista plástico, profesor en la Universidad de la República (UdeLaR) en Montevideo, Uruguay <guigou.nicolas@gmail.com>.

\begin{tabular}{|c|c|c|c|c|c|}
\hline Civitas & Porto Alegre & v. 14 & n. 3 & p. 437-449 & set.-dez. 2014 \\
\hline
\end{tabular}

A matéria publicada neste periódico é licenciada sob forma de uma 


\section{La Kabalah globalizada entre los devenires minoritarios de Occidente}

Los movimientos de creencias que se nos presentan en la contemporaneidad y cuya piedra angular se encuentra en la Kabbalah ya sea de manera central, o bien como parte de un corpus hermeticum que la incluye y la ingresa a un conjunto de saberes autodefinidos como herméticos, esotéricos, o bien con ambos atributos, resultan fundamentales para comprender los devenires minoritarios de Occidente, sus arqueologías, sus modalidades presentes de producción de sentido en este mundo global.

Ese otro devenir minoritario de Occidente (Guigou, 2013), expresado en buena parte en logias masónicas, rosacruces, o en la inicial y bien ponderada Orden de la Golden Dawn del siglo 19 más una larga e inacabada lista de organizaciones habitantes de la nebulosa mística/esotérica/hermética, ha pasado gradualmente en esta alta modernidad de las lógicas del secreto y el ocultamiento a las de la discreción. Ninguno de los movimientos esotéricos occidentales - esto es, generados en el Occidente geográfico, aunque por cierto poblados de Orientalismo varios en el sentido de Said (2002), y que otrora se manifestaran como secretos, poseyendo, precisamente, en el secreto, la iniciación y la transmisión de una doctrina esotérica y oculta su fervor, se mantienen en este lugar.

La dinámica de la discreción hace que el esoterismo occidental se nos manifieste como habitante y a la vez generador de globalización por medio de internet, en los anaqueles de librerías, en películas y en una variada producción de objetos rituales claramente conformado por organizaciones propositivamente discretas. Esto es, aún secretas en algunos niveles de conocimiento, pero dispuestas a mostrase en estos espacios globales públicos y mediáticos en los que antes no eran visibles.

Por lo dicho, es común que la nebulosa mística/esotérica/hermética se manifieste en el mundo de hoy dispersa en agrupaciones, movimientos, iglesias, órdenes, logias autodenominadas discretas y ya no más secretas. La discreción estriba en someras presentaciones públicas, modalidades acotadas de difusión y afiliación, propagación de parte de la doctrina anteriormente oculta, de las narrativas históricas y fundacionales, de los linajes, a lo que podemos sumar críticas a los discursos de corte estigmatizante, presentaciones por vez primera de rituales templos, reuniones, textos, vestiduras, objetos litúrgicos, o bien de sus autoridades a espacios más amplios y heterogéneos que los integrados por los propios seguidores. Con los movimientos cabalistas, también habitantes y generadores de esta globalización, la situación resulta en 
parte diferente a la expuesta. Si acaso mantienen en común con el resto de las organizaciones integrantes de la citada nebulosa el hecho de propiciar matrices de interpretación y cognición de nuestra globalización, inscribiéndose así no únicamente en el mero habitar de la misma sino también en la gestación de marcos afectivos, simbólicos, cognitivos y prácticos para comprender, actuar y situarse en la globalización (la globalización pasa pues a ser parte del discurso de estos movimientos), la diferencia fundamental se encuentra -al menos entre las principales corrientes cabalistas hoy presentes- en el hecho de que éstas continúan asentándose por una parte en matrices culturales y religiosas judías, al mismo tiempo que las asiste una vocación plenamente universalista en el sentido de pretender transformar las identidades religiosas, sociales y culturales (los estilos de estar, habitar y creer en el mundo) a través de la denominada "sabiduría de la Kabbalah".

Cabe consignar que la vocación universalista de la Kabbalah no es una característica novedosa, ni promovida por primera vez por estos noveles movimientos. Por ejemplo la afamada influencia renovadora del cabalista Isaac Luria (el sagrado Ari) habría colaborado en parte a los fundamentos y renovación de la cábala cristiana y musulmana (Scholem, 2008). Podríamos decir en un sentido que esta vocación universalista es propia de la historia de la Kabbalah, en la medida que se trata de un corpus influenciado por cosmologías varias -entre ellas, sufismo, prácticas yógicas como las enseñadas por Abulafia (Scholem, 2008, p. 206), neoplatonismo, gnosticismo y variados énfasis místicos cristianos-, a la vez que ha sabido afectar, sin duda, modalidades de creencias no inscriptas en el mundo social y cultural judío (ingresan aquí, sin duda, parte de los esoterismos occidentales).

\section{La Kabbalah y sus historicidades}

Desde una mirada histórica, la Kabbalah habría tenido su surgimiento en el siglo 12 y 17, ya desde el inicio marcada por una forma heterogénea y plural, de manera que no puede hacerse referencia a un corpus unificado y homogéneo:

"Hacia 1180, aproximadamente, apareció en el sur de Francia -nadie sabe exactamente cómo ni de quién- el primer escrito de los cabalistas, el libro Bahir, que es, sin duda, uno de los más asombrosos, por no decir increíbles, textos de la lectura hebraica de la Edad Media" (Scholem, 2008, p. 98). El contexto socio-cultural, político y religioso que diera lugar a la emergencia de la Kabbalah precisamente en la Provenza francesa -más concretamente en el Languedoc- en el siglo 12 y 13, era particularmente conflictivo, "[...] una región plagada de tensiones culturales y religiosas y uno de los 
centros principales de la cultura medieval" (Scholem, 2001a, p. 31). La herejía cátara y valdense contra la iglesia católica, los variados movimientos gnósticos, los pasagianos y un relevante número de grupos y corrientes que se oponían al catolicismo dominante, más el florecimiento de las comunidades judías de Languedoc que no habrían sido perseguidas por las cruzadas, habrían sido el caldo de cultivo en el cual se originaría la Kabbalah:

En Marsella, Lunel, Béziers, Narbona, Perpiñán, Carcasona y Tolouse, florecía el estudio de la Torá y el Talmud. Narbona, en particular, podía exhibir una gran tradición de estudios judíos que abarcan varias generaciones. Incluso antes del surgimiento de la Kabbalah, desde el siglo XI, los últimos midrashim tuvieron su origen o fueron corregidos en esta ciudad o localidades vecinas (Scholem, 2001a, p. 35).

La aparición en el siglo 13 del mítico Sefer-ha-Zohar (el Zohar) en la discutible Península Ibérica, libro fundamental de las enseñanzas cabalísticas, de autoría múltiple, aunque centrado en el autor principal Rabbí Mose Sem Tov de León, tanto como las renovaciones llevadas a cabo por Isaac Luria (“el sagrado Ari”) y sus discípulos en la Palestina del siglo 16, en la ciudad de Safed (Scholem, 2008, p. 71), en la cual ingresarían con mayor vehemencia la explicación del origen del Mal y la necesaria acción humana para equilibrar la creación universal, fueron, en la intrincada historia de la Kabbalah, dos mojones fundamentales que tendrán su repercusión en los movimientos cabalistas contemporáneos.

De génesis e influencias heterogéneas, los centros y corrientes cabalistas se habrían expandido rápidamente entre cristianos y musulmanes -particularmente en la España anterior a 1492- llegando en el Renacimiento (Bloom, 1999) a influenciar diferentes corrientes místicas-esotéricas. Uno de los trabajos más importantes que colaboraron a difundir las concepciones cabalísticas, cristianizarlas, y presentarlas a un público más amplio fue el conocido libro de Pico de la Mirándola (De la Mirándola, 1486 [1996]) quien publicara sus Conclusiones philosophicae, cabalisticae et theologicae, colaborando a generar una importante corriente de cabalistas cristianos. Durante el siglo $19 \mathrm{e}$ inicios del siglo 20, la Kabbalah habría caído en franca decadencia dentro del judaísmo, como parte de los movimientos secularizadores, principalmente en Europa Occidental. La salida de multitudes de judíos del judaísmo "de la Edad Media", o bien el abandono de la propia religión judía para abrazar el mundo profano bajo el impacto por la cultura heredada de la ilustración y la voluntad de integración a colectivos nacionales (Johnson, 2010), habría colaborado a 
que la Kabbalah fuera percibida como parte de un conjunto de trastos propios de un judaísmo atrasado y en parte, vergonzante.

De cualquier forma, diversas prácticas cabalistas habrían subsistido ya en el seno más recóndito de la cultura judía, ya bajo otras claves y mezclada con conjuntos de saberes soterrados que eclosionarían en variados movimientos esotéricos occidentales, ya bajo el resguardo de linajes de cabalistas que llegan a la actualidad. Sin embargo, el conjunto de linajes religiosos, el abrevar de éstos en la tradición y al mismo tiempo en la búsqueda de modificación de la misma, ha sufrido de muchas ficcionalizaciones, reconstrucciones y vivificaciones hasta la actualidad.

\section{Kabbalah, linaje y mitos}

Puede entenderse el linaje y su relevancia en términos de legitimación de la tradición, siendo utilizado entre los movimientos cabalistas para mostrar que son los herederos de la verdadera tradición -ante eventuales pugnasremitiéndose entonces a los linajes directamente individuales de los maestros de Kabbalah. La demostración de esta herencia estriba en mostrarse lo más fiel a la tradición, esto es, a la ficcionalidad de la tradición en la cual la Kabbalah se constituye a sí misma como "la revelación de Su Divinidad a Sus criaturas en este mundo" (Bnei Baruch, 2011), al decir del cabalista Baal HaSulam, padre fundador del linaje que diera lugar al contemporáneo movimiento global cabalista Bnei Baruch. Esta peculiar manera de postular el linaje y la tradición supone una lectura singular de la tradición -más inventada que nunca en el sentido de Hobsbawm y Ragner (2003) - en la cual la Kabbalah ya no nos remite a su origen histórico en España y Francia, sino a Egipto, al profeta Abraham y a un linaje que envuelve el desarrollo de la Kabbalah desde una perspectiva mítica iniciada por la revelación divina a Abraham en Babilonia llegando hasta la actualidad. Las lecturas de los movimientos globales de la Kabbalah que poseen su linaje en el marco de la cultura judía, si bien enseñan y difunden a la Kabbakah fuera del judaísmo, rechazan en sus narrativas cualquier origen histórico de la Kabbalah como el señalado por Scholem. También por tanto, cualquier tipo de influencia que eventualmente haya podido tener la Kabbalah, desconociendo por ejemplo la temprana influencia del sufismo musulmán (Scholem, 2001a, p. 30).

Con todo, entre los anhelos universalistas de los cabalistas otrora, y los movimientos que tratan de difundir la Kabbalah en este mundo e integrar a la mayor cantidad de gente posible a sus institutos y grupos de estudio, hay una diferencia fundamental: el tratamiento del secreto y sus derivas. Por una parte en nuestro universo global tenemos una explosión de la Kabbalah y una 
divulgación extrema (pensemos en la adscripción de la artista pop Madonna a la misma), que genera enorme resistencia, no únicamente entre varios grupos e instituciones dedicadas a estos saberes, sino también entre aquellos que se han dedicado a estudiar la Kabbalah como objeto académico histórico o bien literario. Así, por ejemplo, Harold Bloom, el polémico defensor del canon Occidental en el mundo letrado, se refiere a los productos textuales de esta plural, masiva y múltiple explosión cabalística de la siguiente manera: "Los manuales populares de la Cábala no son siempre muy exactos en su contenido, y tienden a estar peligrosamente ansiosos de mezclar la Cábala casi con cualquier otro entusiasmo actual, desde el sufismo hasta el hinduismo (Bloom, 1999, p. 200). El objetivo de Bloom a través de un texto no muy conocido - un bello texto sobre Gershom Scholem, historiador y estudioso académico de la Kabbalah-, son los lectores denominados por el autor como cultos que, como tales, pueden tener acceso al conocimiento de la Kabbalah por medio de la obra de Scholem. De esta manera, y por esta vía regia, "[...] los lectores cultos no necesitan, sin embargo, atenerse a esos manuales" (Bloom, 1999, p. 200). Desde una perspectiva precisamente canónica, no le interesa a Harold Bloom la pureza ni el resguardo del secreto, ya que desde su mirada el mismo no existe, sino traer a escena la manera adecuada de aproximarse a una tradición (esto es precisamente lo que quiere decir la palabra Kabbalah), desde una forma académica, erudita y desencantada, y para ello nos orienta hacia el gran estudioso de esta cosmología, Gershom Scholem. Por su parte, el propio Scholem, advierte frente al diletantismo que ha rodeado a la Kabbalah que para su estudio científico e historiográfico resulta de fundamental relevancia la seriedad del investigador para abordar esta temática:

Particular importancia cobra aquí la responsabilidad del científico, que ha de poner de manifiesto su orientación crítica tanto al efectuar estos trabajos de exhumación, como al analizar los resultados. Porque la fascinación que se desprende de dominios como el de la Cábala ha enredado en sus mallas a todo tipo de charlatanes y mentes confusas ya mucho antes de que los historiadores se dedicasen a ella (Scholem, 2008, p. 3).

Para aquellos que entienden a la Kabbalah como una tradición secreta, la problemática incluye no únicamente una visión desencantada, histórica y académica al estilo de Bloom o Scholem, sino también su masiva difusión. Es así que Kabbalah y globalización parecen al inicio corrientes opuestas y contradictorias. Daría inclusive la impresión que una y otra poseen naturalezas contrapuestas. Sin embargo, una de las características de la alta modernidad 
es postular secretos precisamente para revelarlos. Es así que los movimientos globales de la Kabbalah, tienden a globalizar el secreto, al mismo tiempo que tratan de dar cuenta de este universo globalizado por medio de claves cabalísticas. El propio hecho de develar el secreto, de difundirlo, posee como fuente discursiva explicaciones del "mundo de arriba" y de este "mundo de abajo" expresado por, precisamente, la globalización. Tal es el caso del movimiento cabalista Bnei Baruch, el movimiento más pujante y visible de la actual Kabbalah globalizada.

\section{Bnei Baruch y la globalización de la Kabbalah: entre la tradición y la alta modernidad}

El movimiento cabalista Bnei Baruch -como nos señala su sitio principal en 25 idiomas- fue fundado en tierras de Israel en el año 1991 por Michael Laitman “[...] después del fallecimiento de su maestro, Rav Baruch Shalom HaLevi Ashlag (Rabash). El Dr. Laitman nombró a su grupo Bnei Baruch (hijos de Baruch) para conmemorar la memoria de su mentor" (Bnei Baruch, 2011). Michael Laitman, cabalista de nuestro tiempo y figura principal de Bnei Baruch, posee un linaje demostrable en un sentido histórico, fundamental para legitimar su figura como cabalista, al mismo tiempo que se manifiesta como un seguidor, a la vez que un transformador de los métodos de enseñanza de la Kabbalah. Fue discípulo y fiel secretario del Rav Baruj Shalom HaLevi Ashlag (El Rabash), que a su vez -y el linaje continúa:

[...] fue el primogénito y sucesor del más grande cabalista del siglo XX, Rabí Yehuda Leib HaLevi Ashlag, autor del más exhaustivo y autorizado comentario sobre el Libro del Zohar, llamado Sulam (Escalera), el primero en revelar el método completo para la elevación espiritual. Ésta es también la razón del epíteto de Ashlag, Baal HaSulam (Dueño de la Escalera). Bnei Baruj basa enteramente su método en el camino pavimentado por esos grandes líderes espirituales (Bnei Baruch México, 2011).

Cabe señalar que Michael Laitman trasciende en general el mundo de los cabalistas en varios sentidos. En primer lugar se trata de una figura que posee un pasaje por universidades y academias. En el perfil de su propia página, se cuenta que es "Fundador y Presidente del Bnei Baruj Kabbalah Education \& Research Institute, institución dedicada a la enseñanza y la difusión de la sabiduría de la Cabalá. Profesor de Ontología, doctor en Filosofía y Cabalá, con el grado de Maestría en Biocibernética" (Laitman, 2008a). También en uno de los sitios web más importantes del movimiento cabalista que él dirige, se afirma que "Aunado a su compromiso científico, Rav Laitman ha estado 
profundamente involucrado en la Cabalá desde hace treinta años. Ha publicado cerca de cuarenta libros, traducidos a más de doce idiomas, así como cientos de artículos de Cabalá, y unas 10.000 horas de clases audiovisuales" (Bnei Baruch, 2011).

Por otra parte, Laitman ha trabado relaciones directas con algunos científicos -William Tiller, Fred Alan Wolf y Jeffrey Satinover- que con los matices que puedan tener entre ellos, han venido abogando por una comprensión diferente de la realidad, considerando el rol responsable y hacedor que los seres humanos potencialmente poseen sobre la misma, desde una particularísima lectura de la física cuántica. Los citados científicos se volvieron figuras rutilantes a partir del estreno del afamado film What the bleep do we know?! (2004). Posteriormente, Laitman participó en un film intitulado Ups and downs in San Francisco (Ari Films, 2008) que es presentado como Ari Films de la siguiente manera:

Esta película trata sobre el encuentro de dos mundos. Uno representa la antigua sabiduría de la Cabalá, y el otro, la ciencia moderna en su lucha por encontrar respuestas a través de la investigación. El encuentro aborda la necesidad de la humanidad por encontrar respuestas verdaderas, y donde la Cabalá entra como una ciencia moderna, recientemente revelada al mundo para este propósito (Ari Films, 2008).

Laitman aporta a este campo de saber, en la medida que otorga respuestas al citado trío científico: "En la película, el prominente cabalista Rabí Michael Laitman, $\mathrm{PhD}$, presenta respuestas. Lo que resulta es un interesante debate que da lugar a una revolución en el pensamiento de los científicos" (Ari Films, 2008).

Aparte de la participación en esta película y otras, de un sinnúmero de conferencias y entrevistas en los diferentes medios, del dictado de clases a través del Canal TV Online, de la enorme cantidad de libros y artículos publicados, Laitman también es asesor de la Unesco en temas educativos, participando de debates sobre conflictos en la educación, tal como denota la entrevista que la hiciera la CNN de Chile (CNN, 2012), país que viene enfrentando duros conflictos sociales por esta temática. El movimiento Bnej Baruch con sede central en Tel Aviv posee "[...] miles de estudiantes en el mundo entero. En años recientes, el grupo ha crecido en un movimiento comprometido en proyectos educativos voluntarios, presentando fuentes genuinas de Cabalá en estilo de lenguajes contemporáneo" (Bnei Baruch, 2011). Bnei Baruch tiene miles de estudiantes de diferentes niveles que asisten a los cursos regulares de Kabbalah por Internet, con clases interactivas 
grupales en todo el mundo. Asimismo, cuenta con una importante estructura organizativa presente en una multitud de países -en América Latina ha sido muy exitoso en México, Colombia, Brasil, Argentina, Chile, Costa Rica, Bolivia- que brinda cursos, participa de los congresos internacionales de Kabbalah y difunde las publicaciones y el mercadeo general de Bnei Baruch. Siendo un movimiento exitoso, no ha estado librado de críticas ni de estigmatizaciones, en algunos casos llevadas a cabo por ex integrantes del mismo, y de cuestionamientos en relación a la enseñanza de la Kabbalah, tanto por no ser el reflejo de las enseñanzas del cabalista Baal HaSulam -fundador del linaje de Laitman- como por presentar una visión cuasi monopólica de la misma.

¿Cómo da cuenta el movimiento Bnei Baruch del secreto, la reserva que acompañaron a las cabalistas que mencionan como parte de su protohistoria y la actual difusión extrema de la sabiduría de la Kabbalah? La respuesta es en extremo interesante y se encuentra plasmada en el libro La voz de la Cabalá (Laitman, 2008a) en el que se manifiesta que el divinamente autorizado "desde lo alto" para revelar el conocimiento cabalístico a las masas fue Baal HaSulam (Laitman, 2008b). El mismo habría promovido en Israel la difusión pública de la Kabbalah mediante el humildoso diario gratuito llamado "La Nación" desde el año 1940 (Bnei Baruch, 2011). Continuando con el espíritu del padre fundador, Bnei Baruch estaría entonces autorizado a revelar la sabiduría de la Kabbalah al mundo entero, sin considerar género, clase, etnia, orientación sexual o nacionalidad. Inclusive -si bien es integrado por muchos judíosdiscursiva (y conflictivamente) se aminora la importancia de serlo, tanto como la relevancia del judaísmo como religión.

Hay con todo -y según Bnei Baruch-, un apuro temporal en difundir la sabiduría de la Kabbalah: estaríamos viviendo los tiempos del Mesías. No se trata de un tiempo anterior a la llegada de un mesías de carne y hueso, sino del tiempo de la tribulaciones, de las crisis en diferentes ámbitos -económico, familiar, educacional, ecológico, y demás males sociales- que anuncian un tiempo por venir. El tiempo del Mesías, es el tiempo de la globalización, de la conectividad. La globalización -en tanto comunicación cada vez más intensa entre los seres humanos- es una etapa más en la evolución a un tiempo posterior. La globalización es el tiempo de la comunicación entre los egos, sin propósito consciente, de la interacción sin alma. Al mismo tiempo, en la medida que todo es global, Bnei Baruch utiliza la imagen del conocido "efecto mariposa" para mostrar la interdependencia de unos con otros y los efectos que generamos unos sobre otros, inclusive estando territorialmente alejados. 
La globalización sería uno de los sistemas de conectividad, de intercomunicación, que carece de leyes propias, sino que está ajustado a las leyes de mundos superiores, de acuerdo a este movimiento. Por lo tanto el sujeto debe conocer las leyes que mueven a este mundo, para comprender las leyes que manejan su vida, su sociedad, su entorno. Las leyes son las leyes de la naturaleza: armonía y equilibrio. En la naturaleza esas leyes se manifestarían de forma transparente. En los seres humanos esa desarmonía y desequilibrio provendría de la fragmentación de un alma única que se subdividió en miles de chispas divinas que viven en los seres humanos. Los seres humanos habrían perdido en este mundo el contacto con su creador. En la época mítica de la relación directa entre el ser humano y el creador, el ser humano recibía la inspiración divina otorgando, esto es, era parte equilibrada de la creación. A medida que comenzó a aumentar el deseo de recibir únicamente para sí mismo, independiente del equilibrio del universo y la voluntad el creador, el ser humano pierde posibilidad de comunicarse con él, pierde la oportunidad de recibir y por tanto de otorgar.

El humano pasa a ser una unidad dualista con su animal (ego) guiado por el deseo de recibir y una chispa divina atrapada que está en él como posibilidad. Por ello, los seres humanos tienen inclinación natural hacia el mal "Cree en la Torah como una especia, cree en la inclinación hacia el mal”, porque son guiados por su ego. ¿Qué es el ego? le preguntan Laitman en su programa de televisión del Canal de Kabbalah: "El ego es querer perjudicar al otro, aprovecharme del otro" - contesta el cabalista Laitman (Cabalá Tv, 2009). La única salida posible, ya que el ego es guiado por el deseo y el deseo por el sufrimiento, es llegar a la máxima tensión de este deseo: el deseo del creador, de aprender, justamente Kabbalah. Por eso el estudio de la Kabbalah es el único camino para llegar a volver a estar armonía con el creador y de allí con el mundo, los otros y la naturaleza. Habría dos caminos entonces en estos tiempos del Mesías: aprender por medio del sufrimiento, esto es, continuar viviendo crisis hasta que aprendamos a salir de nuestro ego, o bien, someternos al conocimiento cabalístico que solucionará la vida en este mundo, porque conoce las leyes que lo determinan y que no pertenecen a él. El mundo tal como lo conocemos sería un mundo de efectos, no de causas. Las causas se encontrarían en otras esferas espirituales que determinan férreamente el devenir de éste. Nuestro mundo es el mundo de las ramas, no de las raíces. La urgencia es tal, que se admiten discípulos que antes no hubieran entrado a los círculos cabalistas. Es necesario transformar el mundo a través de la sabiduría de la Kabbalah. 


\section{Los orígenes y el destino de la Kabbalah}

Los orígenes de la Kabbalah en las narrativas de Bnei Baruch distan bastante de la visión histórica de Scholem. Ellos remontan el origen de la Kabbalah a Abraham, Moisés y un entrecortado linaje que llegaría hasta el día de hoy (Laitman, 2008b). Por otra parte, el propósito de la Kabbalah es colaborar al equilibrio. Esto es, todo sale mal porque el hombre recibe mal y otorga peor. La tradición cabalística Luriana estaría presente en el sentido que el desequilibrio del hombre y su eventual ajuste fue parte del proceso de la creación. Entonces todos volveríamos a hacer un alma única. El hombre debe terminar la tarea que le fue asignada y que desconoce. Cada generación tiene su manera de aprender Kabbalah. Hay veces que el método no coincide con las almas que bajan al mundo (transmigración de las almas). La suerte de esta etapa es que hay una nueva generación y un nuevo método, siguiendo el destino que ya está escrito.

El hecho que dentro de la cosmología cabalística el ser humano tenga una función fundamental en el equilibro del Universo, aproxima (y en mucho) al movimiento Bnei Baruch a las corrientes autopoiéticas. El ser humano debe descubrir las causas que determinan su trayecto (que no son de este mundo) para comprender el rol que desempeña en la naturaleza y el equilibro de lo creado. Y siendo antropocentrismo mediante, el ser humano debe llegar a una plena comunicación con la Divinidad, de manera que toda la creación se regenere, esto es, se extirpe el Mal, el desequilibrio de la creación. La humanidad toda, entonces, se vuelve un polo fundamental del equilibrio universal y única posibilidad de mejorarlo y llevarlo a la armonía. Esta concepción de un sujeto activo en la gestión del Universo todo, ha tenido particular impacto entre los seguidores del movimiento Bnei Baruch.

\section{Presencia, no presencia y sujeto productor}

En el mundo virtual, de la no presencia de lo real, la enseñanza de la Kabbalah debería ser un problema. Todo lo contrario, ya que lo que veo no es real, es una envoltura, por lo tanto estudiar por internet e interactuar es tan real como hacerlo físicamente.

El mundo físico, el mundo de la percepción, no es un mundo verdadero, sino limitado por los sentidos. Por lo tanto el dictado de cursos por internet, la utilización de todos los medios virtuales de interacción virtual que incluyan la difusión, el aprendizaje y la enseñanza de la Kabbalah son parte de las condiciones contemporáneas para transmitir la Kabbalah. La Kabbalah de la globalización no únicamente debe comprender a esta última como parte de un 
proceso evolutivo material y espiritual que interconecta a los seres humanos. También las herramientas interactivas que otorga esta globalización, son parte del designio para que la Kabbalah tenga un lugar principal y relevante en este mundo.

\section{Conclusiones}

Los movimientos como Bnei Baruch atraen una imagen en que tratan de volver al sujeto como parte fundamental del equilibrio universal. Su incidencia en el "teatro de este mundo" es entenderlo como un sistema intercomunicado que obedece a reglas que le resultan ajenas. El ser humano debe conocer las reglas que lo gobierna y gobiernan al Universo y a la Naturaleza para llegar al equilibrio. Dado que el equilibro definitivo de la creación depende de él, es fundamental que despierte a la Kabbalah. De esta forma, por una parte se llama a la responsabilidad individual, por otra, a los aglutinamientos.

Como movimiento transformador de creencias, no absorbe las singularidades identitarias para mantenerlas en su lugar, sino trata de convertirlas a los propósitos que persiguen. Se trata de un movimiento plenamente sustitutorio, en lo que no conviven adscripciones o cosmologías contrapuestas. Por otra parte, en el monopolio de la enseñanza de la Kabbalah, en la urgencia temporal por develar el secreto, muestran que la discreción (o la ausencia de ella), depende de fuerzas de lo alto. Como movimiento transformador y dador de sentido en nuestra alta modernidad, el movimiento cabalista Bnei Baruch se presenta públicamente como develador de las determinantes de la vida humana, y al mismo tiempo, le brinda a sus seguidores la certeza de ser parte activa en la mejora de la sociedad, la naturaleza y el Universo en general, perspectiva sin duda fascinante, en una época en la cual la autopoiesis, y la preeminencia de los sujetos y sus acciones, se vuelve un lugar común en las más diversas cosmologías sociales.

\section{Referencias}

ARI Films. UPS and downs in San Francisco. Produção de Ari Films. Tel Aviv: 2008. BNEI BARUCH. ¿Qué es Bnei Baruch? 2011 <www.cabalacentroestudios.com/bneibaruch> (12 diz. 2013).

BNEI BARUCH MÉXICO. Cabalá auténtica: la ciencia que cambiará tu vida. 2011. $<$ http://bneibaruchmexico.blogspot.com/> (4 out. 2013).

BLOOM, Harold. Scholem. In: Esther Cohen (Org.). Cábala y desconstrucción. Barcelona: Azul-Unam, 1999. p. 200-214.

CABALÁ TV. ¿Qué es el ego que tengo que deshacerme de él? 2009 <www.youtube. $\mathrm{com} /$ watch $\mathrm{v}=\mathrm{hE} 4 \mathrm{~m} 65 \mathrm{~m} 5 \mathrm{Jnc}>(10 \mathrm{diz} .2013)$. 
CNN Chile. Entrevista al Dr. Laitman, 1 maio 2012 <www.cnnchile.com/ nacional/2012/05/01/conozca-el-innovador-modelo-educativo-del-academicomichael--laitman/> (4 jan. 2013).

DE LA MIRÁNDOLA, Pico. Conclusiones mágicas y cabalísticas. 2. ed. Barcelona: Ediciones Obelisco, [1986] 1996.

GUIGOU, L. Nicolás. La institucionalización del pensamiento de Gilles Deleuze en el campo de las ciencias de la comunicación, la antropología social y las ciencias sociales. Deriva de las artes de domesticar un pensamiento. In: L. Nicolás Guigou; E. Alvarez (Orgs.). Abordajes hacia una etnografía de la comunicación contemporánea. Montevideo: Editorial EP-Universidad de la República, 2013. p.11-24.

HOBSBAWN, Eric; RANGER, Terence. The invention of tradition. 9. ed. Cambridge: Cambridge University Press, 2003.

JOHNSON, Paul. La historia de los judíos. 2. ed. Barcelona: Editorial Zeta, 2010.

LAITMAN, Michael. La voz de la Cabalá. Brooklyn: Editorial Laitman Kabbalah Publisher, 2008a.

LAITMAN, Michael. Blog personal de Michael Laitman. 2008b < http://laitman.es/> (4 jan. 2014).

SAID, Edward W. Orientalismo. 4. ed. Barcelona: Editorial Debate, 2002.

SCHOLEM, Gershom. Los orígenes de la cábala - Tomo I. 3. ed. Buenos Aires: Paidós, 2001a.

SCHOLEM, Gershom. Los orígenes de la cábala - Tomo II. Buenos Aires: Paidós, $2001 b$.

SCHOLEM, Gershom. La cábala y su simbolismo. 14 ed. México D. F.: Siglo XXI, 2008.

What the bleep do we know? Direção de William Arntz, Besty Chasse e Mark Vicente. Distribuye: Roadside Attractions. San Francisco, 2004.

Autor correspondente:

Lelio Nicolás Guigou Mardero

Juan Carlos Gómez 1388 - apto. 902

Ciudad Vieja

11000 - Montevideo, Uruguai

Recebido em: 6 fev. 2014

Aprovado em: 26 jun. 2014 